\title{
Recruitment of Juvenile Red Drum in North Carolina: Spatiotemporal Patterns of Year-Class Strength and Validation of a Seine Survey
}

\author{
NATHAN M. BACHELER* \\ Center for Marine Sciences and Technology, Department of Zoology, North Carolina State University, \\ 303 College Circle Drive, Morehead City, North Carolina 28557, USA \\ Lee M. Paramore \\ North Carolina Division of Marine Fisheries, \\ Post Office Box 539, 604 Harbor Road, Wanchese, North Carolina 27981, USA \\ JEFFREY A. BuCKEL \\ Center for Marine Sciences and Technology, Department of Zoology, North Carolina State University, \\ 303 College Circle Drive, Morehead City, North Carolina 28557, USA

\section{FREDERICK S. SCHARF} \\ Department of Biology and Marine Biology, University of North Carolina-Wilmington, \\ 601 South College Road, Wilmington, North Carolina 28403, USA
}

\begin{abstract}
Sixteen years of data from a North Carolina Division of Marine Fisheries seining survey were analyzed to assess the validity of the survey, describe spatial and temporal patterns in recruitment of red drum Sciaenops ocellatus, and evaluate factors that potentially contribute to recruitment variation. Overall, 11,817 age-0 red drum (total length $=11-104 \mathrm{~mm}$ ) were collected in the survey during 1991-2006. Annual estimates of red drum recruitment were variable over time and showed no long-term trend. The dome-shaped catch-perunit-effort (CPUE) pattern of all annual cohorts indicated that the seine survey captured peak abundance levels each year; the spatial coverage of the survey also appeared to be adequate. Regional correlations within North Carolina were strongest for areas that were adjacent to one another, and the North Carolina statewide index was not correlated with indices from Florida or Texas, suggesting that factors controlling recruitment of red drum operate at a scale of tens to hundreds of kilometers. Age- 0 red drum were caught at temperatures ranging from $8.5^{\circ} \mathrm{C}$ to $33.5^{\circ} \mathrm{C}$ and at salinities from 0.0 to 34.7 practical salinity units (psu; $1 \mathrm{psu} \approx 1 \%$ ). A generalized additive model explained only $8.1 \%$ of the variation in age- 0 abundance, suggesting that early juvenile abundance cannot be predicted with these abiotic factors. Variation in loss rates of age- 0 red drum appeared to be independent of variation in cohort density. The CPUE of age-0 red drum was correlated with harvest of age- 2 fish 2 years later, suggesting that additional modification of year-class strength after the early juvenile stage is moderate or weak. Results of this study have improved our understanding of red drum recruitment patterns while simultaneously validating the seine survey.
\end{abstract}

There is broad interest from both fisheries ecologists and managers to determine the causes of recruitment variability and develop a valid index of recruitment (for purposes of this study, defined as year-class or cohort strength or the eventual contribution of a year-class to the fishery). Previous studies have shown that processes occurring during fish egg or larval stages are most critical in determining recruitment variability (Houde 1987; Miller et al. 1988; Leggett and Deblois 1994). In this case, a juvenile abundance index (JAI) could be used to predict recruitment into the adult

* Corresponding author: nate_bacheler@ncsu.edu

Received August 15, 2007; accepted November 20, 2007 Published online August 21, 2008 population in future years. Currently, the evidence for the appropriateness of using early juvenile stages to index year-class strength is debatable, as regulation during the juvenile stage has been shown to be important for several species (Sissenwine 1984; Myers and Cadigan 1993; Dingsør et al. 2007).

The most appropriate life stage to use as an index of recruitment in red drum Sciaenops ocellatus is largely unknown, but the topic is important given the unique fishery regulations and the early life history of this species. The red drum is a sciaenid species found along the coasts and throughout estuaries of the Gulf of Mexico and the southeastern USA (Lux and Mahoney 1969). Current red drum regulations in most states are unique, because only subadults (i.e., ages 1-3) are harvested by fishers within a window (i.e., slot) limit 
(Takade and Paramore 2007). The red drum is an important recreational species and-to a lesser extent in recent years-is also an important commercial species throughout its range (NCDMF 2001; ASMFC 2007). Overfishing of red drum occurred in North Carolina and elsewhere throughout the 1980s and early 1990s due to underregulation of fishing for all life stages (Murphy and Taylor 1990; McEachron et al. 1998; NCDMF 2001). Strict regulatory actions enacted in the 1990s, which included reductions in bag limits and the implementation of minimum and maximum size limits, have led to improvements in survival (NCDMF 2001; Takade and Paramore 2007; Bacheler et al., in press). The current use of slot limits for red drum in most states affords protection for all reproductively mature fish (Ross et al. 1995). The short time lag between the early life history of red drum and their harvest suggests that factors affecting these early stages will have consequences for the fishery.

Red drum spawn in inlets and passes throughout the species' range (Pearson 1929; Peters and McMichael 1987), and recent evidence suggests that spawning can occur far upstream from inlets near the mouths of bays, rivers, and lagoons in some areas (Johnson and Funicelli 1991; Ross et al. 1995; Luczkovich et al. 1999; Barrios 2004). Based on evaluation of gonadosomatic indices and maturity stages, Ross et al. (1995) determined that peak spawning occurred in August and September in North Carolina. Red drum larvae use tidal or wind-driven currents for transport, and early juveniles settle along marsh edges with muddy or sandy bottoms or in seagrass meadows composed of shoal grass Halodule wrightii or turtle grass Thalassia testudinum (Holt et al. 1983; Rooker and Holt 1997; Stunz et al. 2002). Larger juveniles are often found in the upper reaches of estuaries and low-salinity coastal creeks and bays (Peters and McMichael 1987; Daniel 1988; Ross and Stevens 1992). Juvenile and subadult red drum remain in shallow estuarine habitats during the first 1-2 years of life except during periods of extremely cold weather in winter, when fish may temporarily leave shallow-water habitats for deeper channels (Wenner et al. 1990). Age-0 red drum are vulnerable to seining in estuaries and tributaries during their first fall.

In 1991, the North Carolina Division of Marine Fisheries (NCDMF) began a fall seining survey to generate a JAI for age- 0 red drum and to identify and characterize red drum nursery areas. The NCDMF uses the JAI to assess recruitment and as a tuning index for the North Carolina red drum stock assessment (Vaughan and Carmichael 2000; Takade and Paramore 2007). Despite its importance to red drum management, the JAI survey has never been validated as an accurate predictor of year-class strength. Furthermore, the recruitment patterns of age- 0 red drum in North Carolina have never been comprehensively described.

Here, we analyze 16 years of the JAI seine survey in North Carolina to address three broad topics. First, we assess the validity of the JAI survey in North Carolina. We determine (1) whether the computational form of the JAI influences the abundance signal, (2) whether the pulse of age- 0 red drum recruitment is captured each fall, and (3) whether there are regions that are not supplying information to the JAI. Second, we describe the spatial and temporal patterns of red drum recruitment in North Carolina. For instance, at what spatial scale do factors controlling red drum recruitment operate, and can abiotic factors explain variation in abundance and distribution of early juveniles? Last, we evaluate factors contributing to recruitment variation. We determine whether density-dependent loss is observed for age- 0 red drum, and whether age- 0 relative abundance is useful for predicting future recruitment to the fishery.

\section{Methods}

Juvenile abundance index sampling design.-The NCDMF seined a total of 21 fixed stations each year in North Carolina between 1991 and 2006 (Figure 1). These fixed stations were originally chosen because of their accessibility and productivity from prior scoping work and were assumed to be representative of North Carolina estuaries. Two fixed stations were relocated after 1998 due to extensive growth of widgeon grass Ruppia maritima along the shoreline or due to waveinduced erosion: station 115 was moved to station 142 in the Neuse River (NEUSE), and station 134 was moved to station 143 in the Pamlico River (PAMLICO; Figure 1). Both new stations were relocated less than 1 $\mathrm{km}$ from the previous station, and catchability was assumed to be unchanged. In addition, station 402 in the Outer Banks (OBX) was discontinued after 2001 due to shoreline development; therefore, 20 fixed stations were seined during 2002-2006.

A single seine was pulled at each fixed station biweekly from early September to late November of each year, resulting in six seine samples per station annually. These months were chosen in an attempt to capture the entire period of red drum juvenile recruitment, beginning with the initial settlement of postlarvae in early September and ending in late November, when fish begin to emigrate to deeper water to avoid cold water temperatures. During some biweekly periods, logistical constraints or poor weather prevented sampling at some of the sites; in those periods, catch per unit effort (CPUE; defined as the 


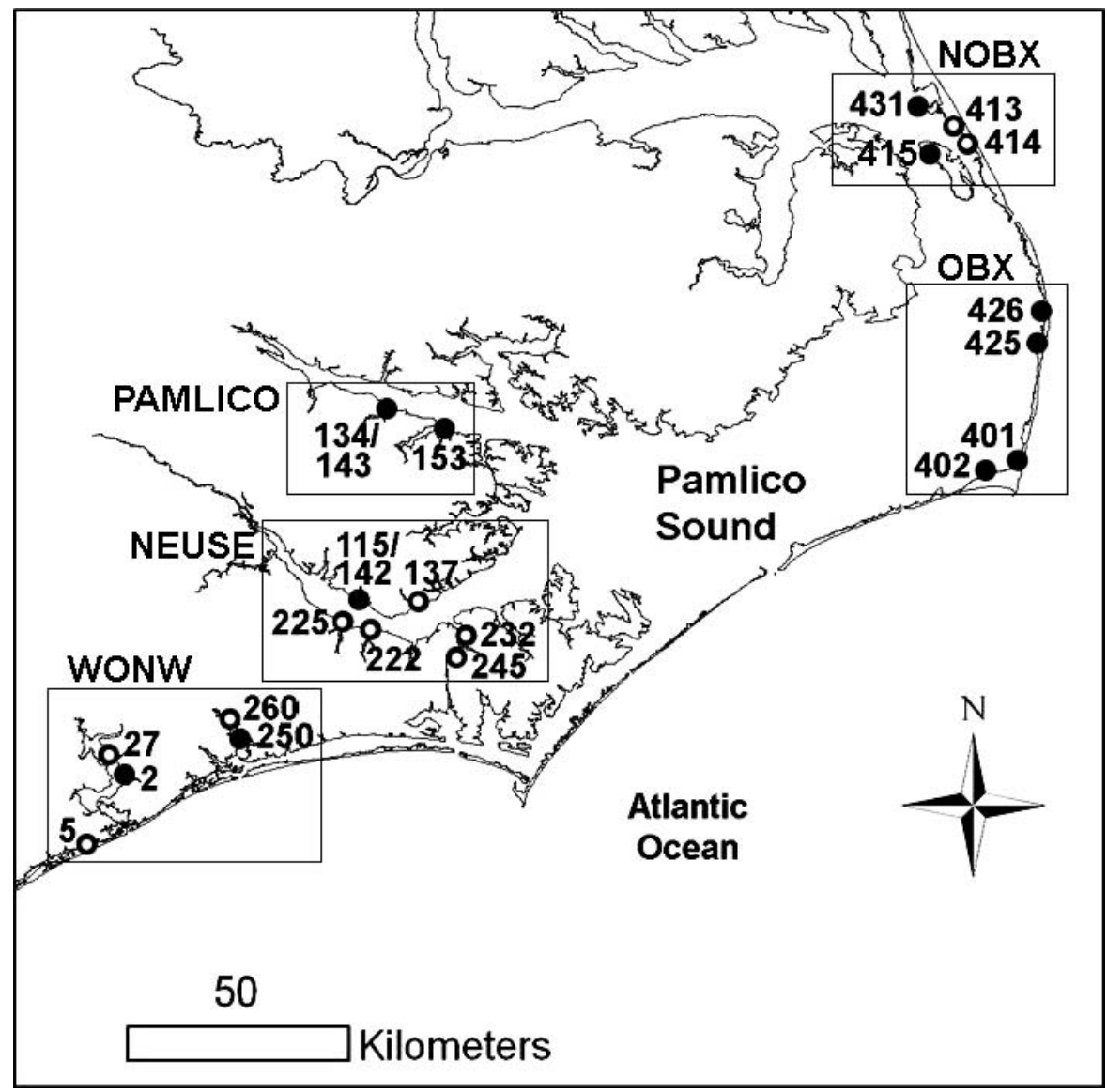

FIGURE 1.-Map of stations sampled by beach seine in North Carolina during 1991-2006 to determine age-0 red drum abundance. Boxes surround stations within each of five regions (NOBX = northern Outer Banks, OBX = Outer Banks, PAMLICO $=$ Pamlico River, NEUSE $=$ Neuse River, and WONW $=$ White Oak-New rivers). Open circles indicate fixed stations with high red drum catch per unit effort (CPUE; number captured per seine haul; $n=10$ stations), and filled circles indicate fixed stations with low CPUE ( $n=11$ stations); high- and low-CPUE designations were determined from cluster analysis.

number captured in one seine deployment) was calculated based on the remaining seine deployments.

Sampling gear and deployment techniques were consistent over time and space. Seining was conducted using a hand-held bag seine (18.3 m long; $1.8 \mathrm{~m}$ high; 6.4-mm bar mesh in the body; $3.2-\mathrm{mm}$ bar mesh in the bag). One end of the net was held at the shoreline, and the other end was fully extended perpendicular to the shoreline. The offshore end of the net was then pulled in a quarter sweep in the direction of water flow and returned to the shore, while the beach end of the net was held stationary. Total bottom area sampled was approximately $255 \mathrm{~m}^{2}$ for each sweep. Red drum were enumerated, and a subsample was measured for total length (mm). Environmental data (water temperature, salinity, depth, bottom type, and vegetation) were also recorded.
Validity of the juvenile abundance index survey.We first evaluated the influence of the computational form of seven indices on the observed trends in abundance. We calculated the JAI for each year using both the arithmetic and geometric mean CPUE in three ways: (1) mean of all seine hauls within a year, (2) mean of all seine hauls in only the middle four biweekly sampling periods, and (3) single-highest biweekly CPUE averaged across all stations (determined separately for arithmetic and geometric means). The second JAI was evaluated to assess whether low capture rates in early September or late November (due to late immigration and early emigration, respectively) had a large influence on abundance trends through time. When catches contained no age- 0 red drum, a value of 1.0 was added to raw catch data before log transformation to calculate geometric means. 
Since age-0 red drum abundance was related to water quality variables (see Results), a seventh JAI was calculated that involved generalized additive model (GAM) correction for the influence of interannual variability in water quality at fixed stations. We used the GAM correction based on the method described by Wiedenmann and Essington (2006). Briefly, catch data were $\log$ transformed $\left(\log _{e}[\right.$ catch +1$\left.]\right)$ and the residual catch rate for each seine haul was calculated as

$$
\log _{e}(\text { catch }+1)-\bar{Y} \text {, }
$$

where $\bar{Y}$ is the mean log-transformed catch rate. Residual catch rate was used as the response variable in the GAM. Water quality variables were entered sequentially into the model; residuals from the first predictor variable $\left(x_{1}\right)$ were used as the response for the second-best predictor $\left(x_{2}\right)$ and so on. The GAM was then used to weight the effort of each seine haul $\left(q_{i}\right)$ based on the collection of age- 0 red drum by use of the following equation:

$$
q_{i}=\exp \left[\sum_{j} S\left(x_{j}\right)+\bar{Y}\right]-1,
$$

where $\Sigma_{j} S\left(x_{j}\right)$ is the predicted residual red drum catch rate after accounting for the influence of predictor variables. Effective sampling effort for each year $t$ was calculated as $\Sigma q_{i}(t)$, and the GAM-corrected JAI in year $t$ was calculated as the number of age- 0 red drum caught in year $t$ divided by the effective sampling effort in that year. Each explanatory variable was fit with $4 \mathrm{df}$ using the Gaussian family model with an identity link function, because this model could account for negative values in the response variable. The GAM was constructed in S-PLUS 2000 (Insightful Corporation, Seattle, Washington). Pearson's product-moment correlation analysis was used to test the degree of correlation among indices. Significance was determined at $P$-values less than or equal to 0.05 for all statistical tests unless otherwise noted.

We also wanted to evaluate the temporal robustness of the seine survey (i.e., determine whether the peak in age-0 red drum recruitment was captured by the survey each year). We calculated the arithmetic mean CPUE across all stations within each of the six biweekly sampling periods for each year separately. We also used cluster analysis to group homogeneous years based on their biweekly patterns of age-0 CPUE. Cluster analyses were completed using Ward's method of linkage and Euclidean distances (McCune and Grace 2002) in Statistica version 6.1 (StatSoft, Inc., Tulsa, Oklahoma). Clusters were determined at the $45 \%$ information remaining level, which provided a good compromise between loss of information and simplic- ity or interpretability of groupings (McCune and Grace 2002). Mean CPUE was then determined for each cluster separately.

To evaluate the spatial adequacy of the JAI survey, we assessed whether a single region or station tended to dominate the JAI or, alternatively, whether catches were similar across regions and stations. We used cluster analysis to objectively group stations based upon their mean annual CPUE trends over time. We again used Ward's method of linkage and Euclidean distances (McCune and Grace 2002) in Statistica 6.1. Groups were determined at the $45 \%$ information remaining level. Combining stations together into relatively homogenous groups allowed us to examine the spatial patterns of recruitment.

Patterns of red drum recruitment.-We were also interested in determining the spatial scale at which factors influencing red drum recruitment operated. For these analyses, individual stations were grouped into five regions: northern Outer Banks (NOBX), OBX, PAMLICO, NEUSE, and the White Oak and New rivers (WONW). We tested for regional-scale relationships through correlation analysis of intrastate CPUE trends.

Factors controlling recruitment, however, may have operated at larger geographic scales. To evaluate the possibility of larger-scale geographic relationships, we also tested for the existence of interstate correlations. Indices of age-0 red drum abundance were not available from the neighboring states of Virginia, South Carolina, and Georgia (Vaughan and Carmichael 2000). Thus, we compared the North Carolina statewide index to three indices from Florida (Indian River lagoon, Charlotte Harbor, and Tampa Bay; D. Tremain and M. Murphy, Florida Fish and Wildlife Conservation Commission, personal communication) as well as a Texas statewide index (Martinez-Andrade et al. 2005) using Pearson's product-moment correlation analysis.

In addition, we constructed a separate GAM to relate the abundance of age- 0 red drum to environmental variables in North Carolina. A GAM is a generalization of a generalized linear model; its main advantage over traditional regression techniques is its capability for modeling nonlinearities, which are common in ecological studies, by using nonparametric smoothed curves (Hastie and Tibshirani 1990). The GAM replaces the traditional least-squares estimator (multiple linear regression) with a local smoother; here, we used the cubic spline smoother $(s)$, which is a piecewise cubic polynomial with pieces joined together at unique values of $x$ in the data. We only used temperature, salinity, and dissolved oxygen as explanatory variables because each was recorded consistently throughout the 
time period of the survey; bottom type and vegetation were only rarely recorded. Each explanatory variable was fitted to the response variable $\left(\log _{e}[\right.$ CPUE +1$\left.]\right)$ with $4 \mathrm{df}$ using the Gaussian family model and identity link function. The GAM was constructed in S-PLUS 2000 (Insightful Corporation).

Factors controlling recruitment variation.-We tested for density dependence in the fall loss rates of age- 0 red drum in two ways. First, we examined the relationship between peak CPUE and late-November CPUE across all years of the study. A linear relationship would suggest that age-0 red drum loss rates during the first fall varied independent of cohort density. We fitted both a linear model (late-November $\mathrm{CPUE}=[a \times$ peak CPUE $]+b)$ and a Beverton-Holt model (late-November CPUE $=[a \times$ peak CPUE $] /[b+$ peak CPUE]) to the data using nonlinear least-squares regression. We chose the Beverton-Holt model because it assumes that the mortality rate of a cohort is linearly dependent upon the number of fish in that cohort (Hilborn and Walters 1992); the relation between successive stages of a cohort is therefore asymptotic when density is high. To determine the most parsimonious model, we used Akaike's information criterion (AIC; Burnham and Anderson 2002) and residual analysis. The AIC method penalizes increases in the number of estimated parameters and rewards goodness of fit. If AIC values from the two models differ by less than 2, they are indistinguishable from one another (Burnham and Anderson 2002); in our case, the loss rates would then be considered density independent.

As an additional test for density-dependent loss, estimates of fall age- 0 red drum loss rate (mortality + emigration) were evaluated in relation to the annual CPUE estimates. Age- 0 fall loss rate was estimated from the declining slope of the regression of $\log _{e}$ (arithmetic mean biweekly CPUE) against sampling date (Ricker 1975). Early and late-September CPUE data were not included in loss rate estimates because in each year, full recruitment of the entire cohort to the seine gear did not occur until early October. The lack of a significant relationship between age-0 loss rate and age-0 CPUE would provide additional evidence that fall loss rate varied independent of cohort density.

To assess the forecasting capabilities of the JAI, we related a lagged age- 0 index to two indices of age- 2 abundance. We used commercial and recreational fishery landings in North Carolina as proxies for age2 abundance, since catches in both fisheries are primarily composed of age- 2 fish due to centering of the slot limit on this age-group (Bacheler et al., in press). The recreational age- 2 index was compiled from Marine Recreational Fisheries Statistics Survey data, and the commercial index was built using NCDMF trip ticket data.

\section{Results}

Overall, 11,817 age-0 red drum were collected by the JAI seine survey in North Carolina during 19912006. Total length of red drum ranged from 11 to 104 $\mathrm{mm}$ (mean $=40.3 \mathrm{~mm}$; SE $=0.2$; measured $n=8,000$ fish). Mean CPUE across survey years varied among stations, ranging from a low of 0.6 fish/seine haul at station $425(\mathrm{OBX})$ to a high of $30.8 \mathrm{fish} / \mathrm{haul}$ at station 137 (NEUSE); however, most stations yielded CPUEs between 2 and 8 fish/haul (Table 1). Salinity and dissolved oxygen varied considerably among stations, while temperature was more consistent (Table 1).

\section{Validity of the Juvenile Abundance Index Survey}

All seven methods for calculating the JAI were significantly and positively correlated (all $R^{2} \geq 0.83$, all $P \leq 0.05$; Figure 2A). Red drum recruitment was highly variable through time; peaks indicated strong year-classes in 1991, 1993, 1997, 2004, and 2005, and lows indicated weak year-classes in 1992, 1996, 1999, and 2001 (no significant long-term trend was evident; $P>0.05$ for all indices). All methods of calculation revealed the same peaks and troughs in annual CPUE; thus, the computational form of the index did not influence the temporal trend in the abundance signal. Hereafter, the arithmetic mean of all six biweekly time periods is used as the primary index of red drum CPUE; an added benefit of using this computational form is its consistency with past and present NCDMF analyses. All results presented below were very similar among the six alternative JAI computations.

Cluster analysis detected three different groups of recruitment years based on temporal patterns of biweekly CPUE (Figure 2B). Group 1 included 3 years (1991, 1993, and 1997) and was typified by high, dome-shaped CPUE (maximum CPUE occurred in early October). Group 2 included 4 years (1994, 1998, 2004, and 2005) demonstrating moderate CPUE values that were less variable seasonally (maximum CPUE occurred in late September). The remaining 9 years were clustered into group 3, which was characterized by lower CPUE values with a dome-shaped seasonal pattern that peaked in early October, as was observed for group 1. The dome-shaped temporal patterns in CPUE of all groups indicate that the seine survey captured peak abundance levels of each annual cohort from early postsettlement until the beginning of emigration in late fall or early winter.

Cluster analysis divided stations into two major groups: those with high CPUE ( $n=10$ stations) and those with low CPUE ( $n=11$; Figure 1$)$. Two lines of 
TABLE 1.-Characteristics of fixed stations (see Figure 1 for locations and region code definitions) at which biweekly seining (1991-2006; $N=$ total number of seine hauls) was conducted by the North Carolina Division of Marine Fisheries to construct an annual juvenile abundance index of red drum. Catch per unit effort (number/haul), temperature (temp), salinity (practical salinity units [psu]), and dissolved oxygen (DO) are means (SE in parentheses) across all sampling years.

\begin{tabular}{lllrrrr}
\hline Station & Region code & $N$ & \multicolumn{1}{c}{ CPUE } & Temp $\left({ }^{\circ} \mathrm{C}\right)$ & Salinity (psu) & DO (mg/L) \\
\hline 413 & NOBX & 93 & $12.7(2.5)$ & $20.3(0.6)$ & $9.8(0.5)$ & $9.9(0.2)$ \\
414 & NOBX & 93 & $9.9(1.8)$ & $20.1(0.6)$ & $10.4(0.5)$ & $9.7(0.2)$ \\
415 & NOBX & 93 & $4.1(1.0)$ & $19.5(0.5)$ & $9.6(0.5)$ & $8.9(0.2)$ \\
431 & NOBX & 91 & $3.0(2.5)$ & $19.3(0.6)$ & $6.9(0.3)$ & $9.4(0.2)$ \\
401 & OBX & 92 & $1.7(0.7)$ & $19.9(0.5)$ & $19.8(0.4)$ & $8.9(0.2)$ \\
$402^{\mathrm{a}}$ & OBX & 56 & $5.1(1.8)$ & $19.8(0.8)$ & $20.1(0.4)$ & $6.8(0.3)$ \\
425 & OBX & 93 & $0.6(0.2)$ & $20.1(0.6)$ & $20.4(0.5)$ & $8.6(0.2)$ \\
426 & OBX & 91 & $2.8(0.8)$ & $20.4(0.6)$ & $21.3(0.5)$ & $9.0(0.2)$ \\
134,143 & PAMLICO & 78 & $3.1(0.5)$ & $19.9(0.5)$ & $7.8(0.6)$ & $7.1(0.2)$ \\
153 & PAMLICO & 73 & $3.1(0.5)$ & $20.1(0.6)$ & $9.5(0.5)$ & $7.6(0.2)$ \\
115,142 & NEUSE & 79 & $3.2(0.4)$ & $20.9(0.6)$ & $9.6(0.7)$ & $6.9(0.2)$ \\
137 & NEUSE & 84 & $30.8(5.1)$ & $20.6(0.5)$ & $10.7(0.5)$ & $7.0(0.2)$ \\
222 & NEUSE & 96 & $6.4(1.4)$ & $20.6(0.5)$ & $7.8(0.5)$ & $8.1(0.2)$ \\
225 & NEUSE & 96 & $10.4(1.8)$ & $21.1(0.5)$ & $6.4(0.5)$ & $7.5(0.2)$ \\
232 & NEUSE & 95 & $4.7(0.9)$ & $21.1(0.5)$ & $13.0(0.7)$ & $7.4(0.2)$ \\
245 & NEUSE & 95 & $6.0(0.8)$ & $21.1(0.5)$ & $12.2(0.6)$ & $7.2(0.2)$ \\
2 & WONW & 82 & $6.5(2.5)$ & $20.9(0.5)$ & $16.6(0.7)$ & $7.1(0.2)$ \\
5 & WONW & 93 & $7.6(1.4)$ & $20.4(0.6)$ & $25.2(0.6)$ & $5.7(0.2)$ \\
27 & WONW & 90 & $3.8(0.7)$ & $20.7(0.5)$ & $16.0(0.7)$ & $7.0(0.3)$ \\
250 & WONW & 90 & $1.9(0.7)$ & $20.9(0.6)$ & $21.6(1.0)$ & $6.7(0.1)$ \\
260 & WONW & 90 & $7.0(1.0)$ & $20.6(0.6)$ & $17.4(1.0)$ & $6.7(0.2)$ \\
\hline
\end{tabular}

${ }^{a}$ Station 402 was sampled only during 1991-2001.

evidence support the spatial adequacy of the JAI survey based on cluster analysis results. First, no single region dominated the index (Figure 1). Second, three of the five regions were composed of stations that demonstrated both high and low CPUEs. For instance, five of six fixed stations in NEUSE, three of five stations in WONW, and two of four stations in NOBX were from the high-CPUE group. The exceptions were OBX and PAMLICO, which were composed entirely of stations with low CPUE.

\section{Patterns of Red Drum Recruitment}

Intrastate comparisons of mean CPUE were often correlated except for the OBX region, where catches were generally very low (Table 2). Overall, 3 of 10 Pearson's product-moment correlation coefficients $(r)$ were significant at the 0.05 level, and 5 of 10 were significant at the 0.10 level. Generally, correlations were stronger for adjacent regions. The overall statewide index was most closely correlated with CPUE in NEUSE $(r=0.89)$ and was correlated to a lesser extent with CPUEs in NOBX $(r=0.84)$ and WONW $(r=0.65)$.

Correlations at larger geographic scales, however, were not detected. North Carolina CPUE during 19912005 was not significantly correlated with indices from the three regions of Florida: Indian River $(r=-0.06)$, Charlotte Harbor $(r=-0.20)$, and Tampa Bay $(r=$ 0.20). Furthermore, the North Carolina CPUE was not significantly correlated with the statewide index from Texas $(r=0.52)$, although a positive trend was evident.

Age-0 red drum were caught at temperatures ranging from $8.5^{\circ} \mathrm{C}$ to $33.5^{\circ} \mathrm{C}\left(\right.$ mean $\left.=20.4^{\circ} \mathrm{C} ; \mathrm{SE}=0.1\right)$ and at salinities ranging from 0.0 to 34.7 practical salinity units $(\mathrm{psu} ; 1 \mathrm{psu} \approx 1 \%$; mean $=12.9 \mathrm{psu} ; \mathrm{SE}=0.2$ ). The GAM, however, only explained $8.1 \%$ of the variation in age-0 red drum abundance, even though temperature $(F=7.78, \mathrm{df}=3, P<0.0001)$ and salinity ( $F=4.49$, df $=3, P=0.004)$ were each significant predictors (Figure 3 ). The CPUE of age- 0 red drum was highest at temperatures near $21^{\circ} \mathrm{C}$ and was moderately high within the range of $15-25^{\circ} \mathrm{C}$. Age- 0 red drum CPUE decreased at temperatures outside of this range. Also, CPUE was highest between 0 and 10 psu, declined between 10 and 20 psu, and remained relatively constant or showed another slight mode at around 27 psu (Figure 3). Age-0 red drum CPUE was not significantly related to variation in dissolved oxygen concentration $(F=1.60$, df $=3, P=0.18)$.

\section{Factors Controlling Recruitment Variation}

There was no evidence of density-dependent loss rates for age-0 red drum during fall. Late-November CPUE did not show evidence of reaching an asymptote at large values of peak CPUE (Figure 4A), as would be expected if loss rates were density dependent. Using AIC and residual patterns, we could not distinguish between the density-independent linear model $(\mathrm{AIC}=-1.93)$ and the density-dependent Beverton- 

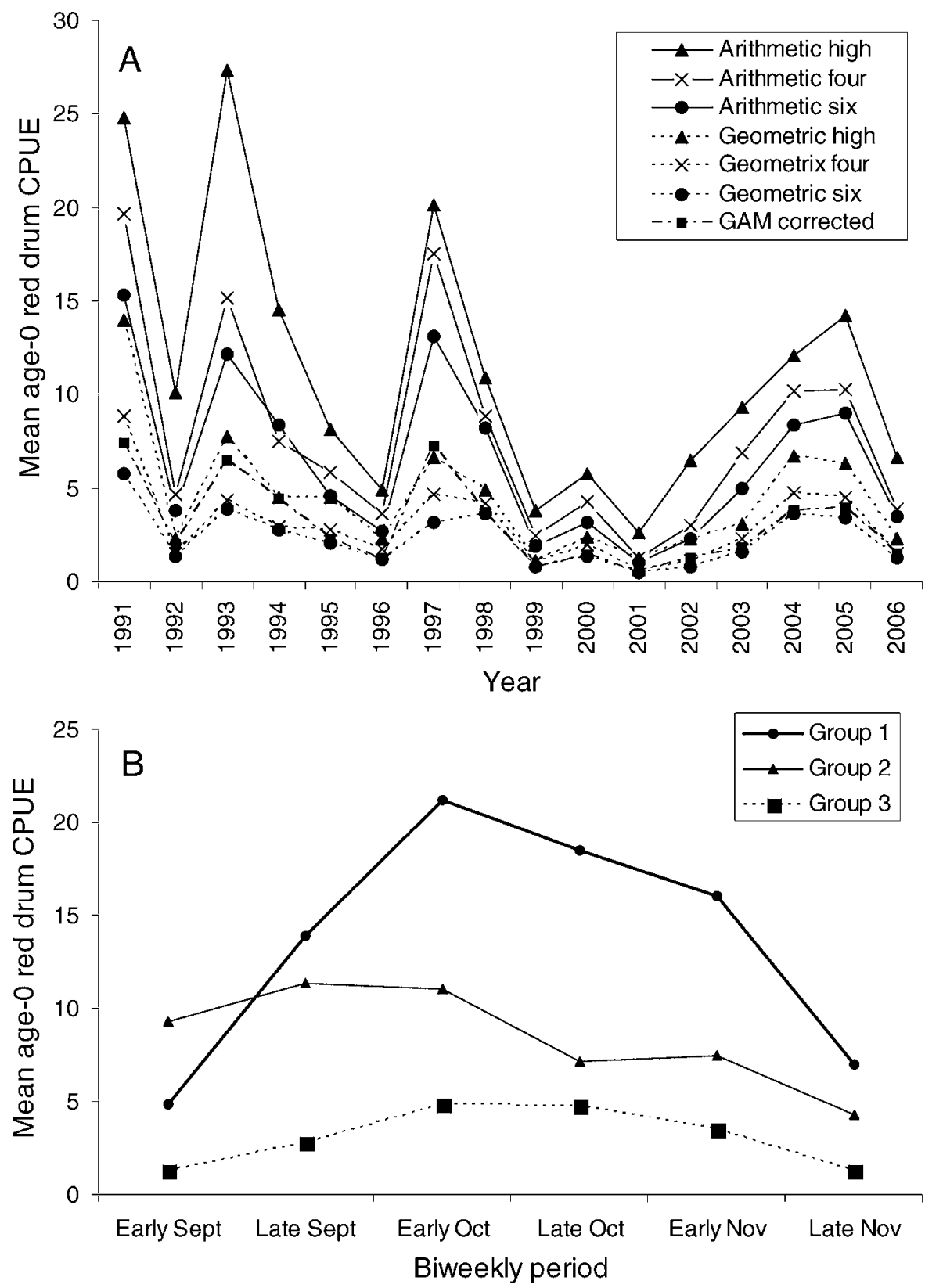

FIGURE 2.-(A) Mean age-0 red drum catch per unit effort (CPUE; number captured per seine haul) in North Carolina, 19912006, as calculated by seven computational forms: highest biweekly arithmetic mean (solid line, triangles), arithmetic mean of all seine hauls in the middle four biweekly sampling periods only (solid line, $X$-symbols), arithmetic mean of all seine hauls in all six biweekly sampling periods (solid line, circles), highest biweekly geometric mean (dotted line, triangles), geometric mean of all hauls in the middle four periods (dotted line, $\times$-symbols), geometric mean of all hauls in all six periods (dotted line, circles), and a general additive model (GAM) corrected abundance index (dashed line, squares); and (B) mean age-0 CPUE by sampling period during fall, where three groupings of recruitment years surveyed by the North Carolina Division of Marine Fisheries (1991-2006) were determined by cluster analysis (group $1=1991,1993$, and 1997; group 2=1994, 1998, 2004, and 2005; group $3=$ the remaining 9 years). 
TABLE 2.-Pearson's product-moment correlation coefficients for comparisons of annual age-0 red drum catch per unit effort (number/seine haul) between pairs of regions within North Carolina (region codes are defined in Figure 1) and between each region and the entire state $(* 0.05 \leq P<0.10 ; * * P<0.05)$.

\begin{tabular}{lcccccc}
\hline Region code & NOBX & OBX & PAMLICO & NEUSE & WONW & Statewide \\
\hline NOBX & 1 & $0.61^{* *}$ & 0.22 & $0.56^{* *}$ & $0.46^{*}$ & $0.84^{* *}$ \\
OBX & & 1 & 0.02 & 0.19 & -0.29 & 0.38 \\
PAMLICO & & & 1 & $0.46^{*}$ & 0.43 & $0.49^{*}$ \\
NEUSE & & & & 1 & $0.53^{* *}$ & $0.89^{* *}$ \\
WONW & & & & & 1 & $0.65^{* *}$ \\
Statewide & & & & & & 1 \\
\hline
\end{tabular}

Holt model (AIC $=-1.04)$, partly because the flexibility of parameter estimation in the BevertonHolt model allows for a near-linear fit to the data in such cases (Table 3; Figure 4A). In addition, loss rates were not significantly correlated with age- 0 CPUE $(r=$ $0.01, P=0.77$; Figure $4 \mathrm{~B}$ ), providing further evidence that loss rates were density independent during the fall.

The annual age- 0 abundance index was significantly correlated with the catch of age- 2 fish 2 years later in commercial fisheries $\left(R^{2}=0.39, P=0.02\right)$ but not with age-2 catch in recreational fisheries $\left(R^{2}=0.11, P=\right.$ 0.26; Figure 5). There was one obvious outlier in each relationship that indicated low age-0 CPUE in 1996 despite the high commercial and recreational landings of 2-year-old fish in 1998. In 1996, intense hurricane activity in North Carolina may have reduced the availability of age- 0 red drum in the habitats sampled by the JAI survey. Both Vaughan and Carmichael (2000) and Takade and Paramore (2007) removed this outlier from the index during recent red drum stock assessments. When this single unusual year was removed from our analyses, the correlations with age0 CPUE significantly improved for both recreational

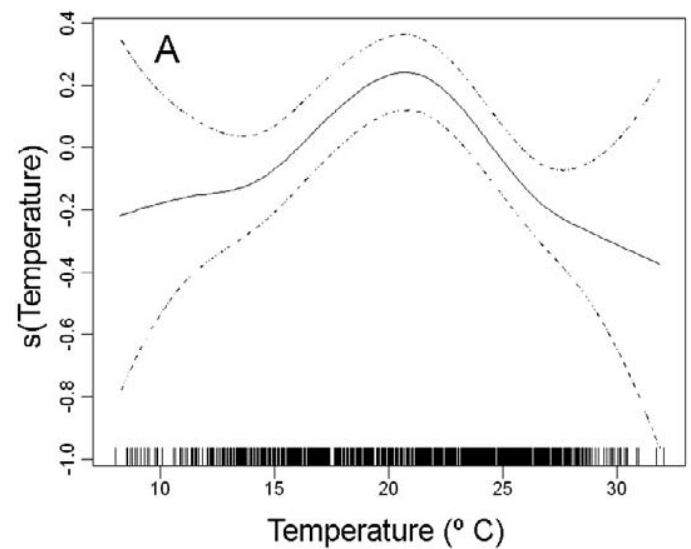

catch $\left(R^{2}=0.60, P=0.002\right)$ and commercial catch $\left(R^{2}\right.$ $=0.62, P=0.001)$.

\section{Discussion}

Validity of the Juvenile Abundance Index Survey

The patterns revealed by the catch data indicate that the NCDMF seine survey sufficiently captured the spatial and temporal pulse of age-0 red drum recruitment in North Carolina waters. The apparent lack of density dependence in loss rates of red drum in their first fall suggests that juvenile abundance may track well with abundance at later ages. The correlations of age- 0 red drum CPUE from the seine survey with age- 2 catch 2 years later support this conclusion. Thus, the JAI survey appears to provide a robust index of age- 0 abundance and should be useful as a valid tuning index for red drum stock assessments in North Carolina.

All methods used to calculate the abundance index of age- 0 red drum in North Carolina were highly correlated ( $R^{2} \geq 0.83$ in all cases), suggesting that the observed interannual patterns of magnitude and variability in age- 0 abundance were real. Since we

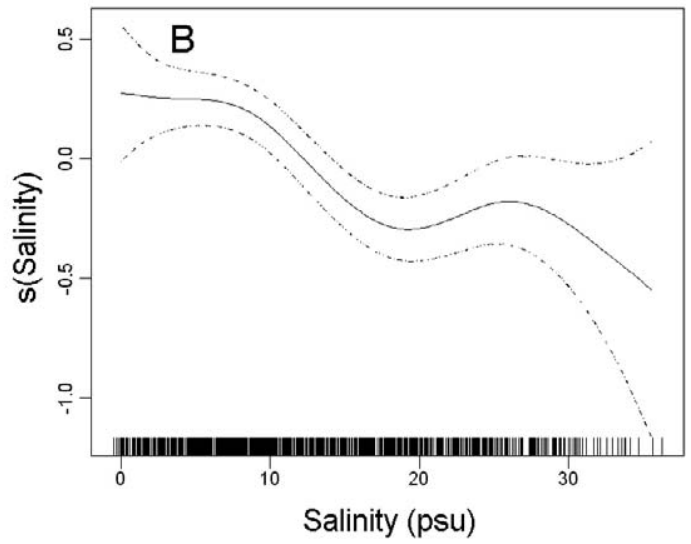

FIGURE 3.-Cubic spline-smoothed generalized additive model plots of the deviation in abundance of age- 0 red drum captured during annual juvenile abundance index seine surveys (1991-2006; North Carolina Division of Marine Fisheries) in relation to (A) temperature $\left({ }^{\circ} \mathrm{C}\right)$ and (B) salinity (practical salinity units [psu]). Tick marks along the $x$-axis indicate sampling intensity; dashed lines show the SE. 

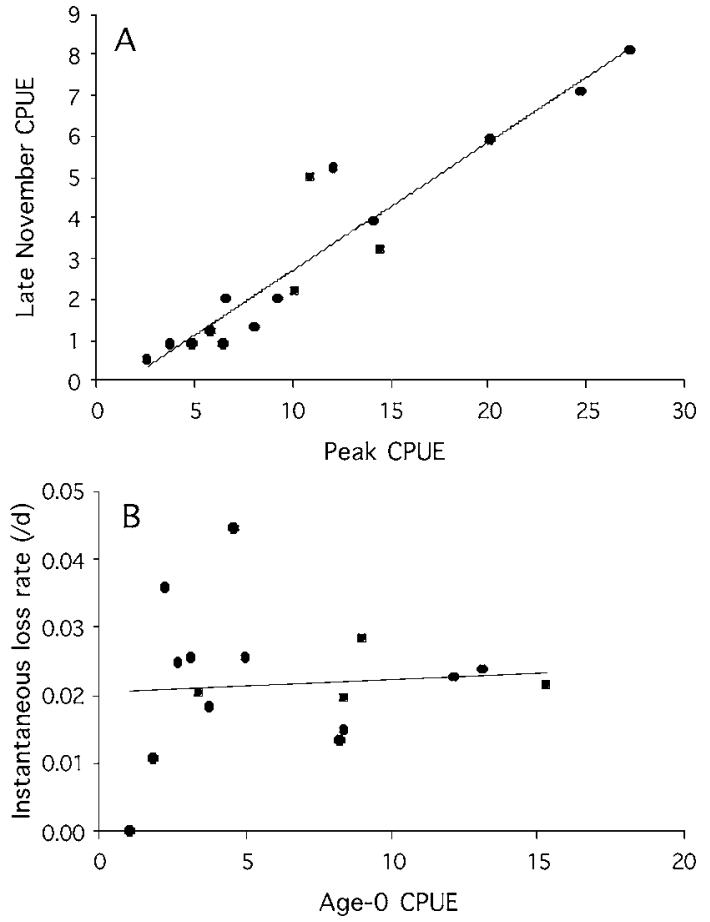

FIGURE 4.-(A) Correlation between late-November catch per unit effort (CPUE; number captured per seine haul) and peak CPUE of age-0 red drum in North Carolina (1991-2006); and (B) instantaneous age-0 red drum loss rate per day as a function of CPUE from the same seining survey. Each point represents a single survey year.

found significant relationships between age-0 abundance and water quality variables, we also used a recently developed GAM approach to calculate a JAI that accounts for interannual variability in water quality parameters (Wiedenmann and Essington 2006). In our case, however, age-0 red drum abundance patterns produced by this method were similar to those of other computational forms; the similarity was probably due to (1) the weak relationship between age- 0 abundance and abiotic factors and (2) the poor explanatory power

TABLE 3.-Linear and Beverton-Holt model fits to age-0 red drum catch per unit effort (CPUE; number/seine haul) in late November $(y)$ as a function of peak CPUE $(x)$ in biweekly collections conducted in North Carolina during 1991-2006. The residual sum of squares (SS), Akaike's information criterion (AIC), and values of the two estimated parameters ( $a$ and $b$ ) are given.

\begin{tabular}{llcccc}
\hline \multicolumn{1}{c}{ Model } & $\begin{array}{c}\text { Functional } \\
\text { form }\end{array}$ & $\begin{array}{c}\text { Residual } \\
\text { SS }\end{array}$ & AIC & $a$ & $b$ \\
\hline Linear & $y=a x+b$ & 10.10 & -1.93 & 0.32 & -0.465 \\
Beverton-Holt & $y=a x /(b+x)$ & 10.72 & -1.04 & 0.26 & -0.004 \\
\hline
\end{tabular}
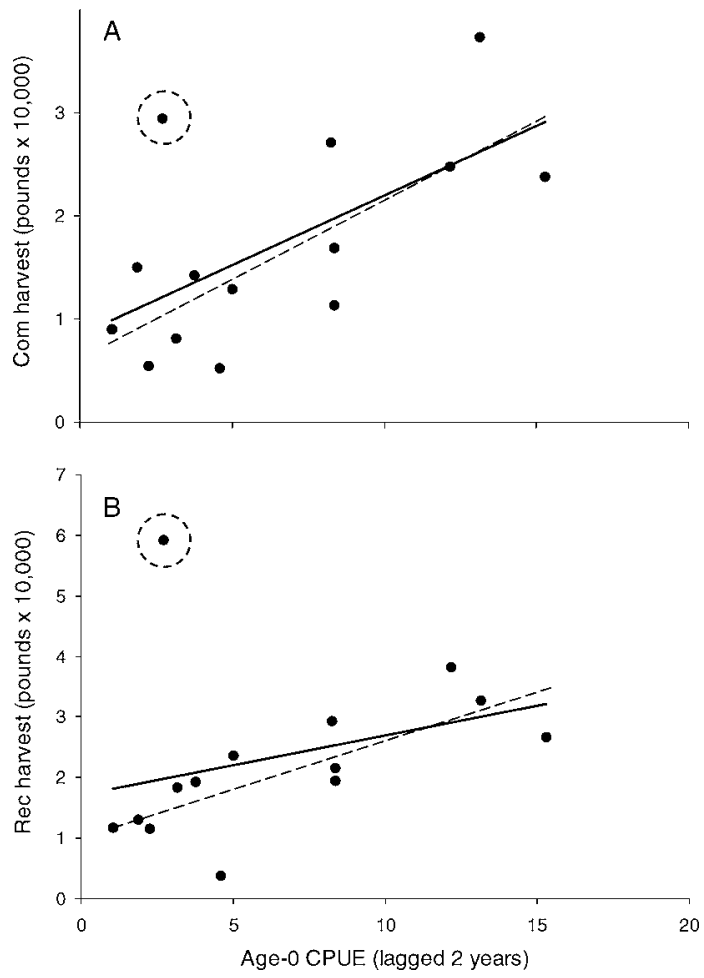

Figure 5.-Age-0 red drum catch per unit effort (CPUE; number captured per seine haul) in annual seine surveys (North Carolina Division of Marine Fisheries; 1991-2006) plotted in relation to (A) pounds of commercial (com) red drum harvest obtained 2 years later and (B) pounds of recreational (rec) harvest obtained 2 years later $[1 \mathrm{lb}=0.45$ $\mathrm{kg}$ ]. Harvest in both fisheries is dominated by age-2 fish (Bacheler et al., in press). An outlier from the 1996 year-class is surrounded by a dashed circle (see Results). Solid regression line is fitted to all data points; dashed line is fitted to all points except the outlier.

of the model (only $8.1 \%$ of the deviance was explained). This GAM-corrected method may be more useful for surveys in which interannual variability in explanatory variables is large and the relationship between fish abundance and those variables is strong and nonlinear.

Fishery-independent sampling programs are extremely important to the success of marine fisheries management. The quality of fishery-dependent data is decreasing in many fisheries due to harvest restrictions and changes in the behavior of fishers; this is particularly true for red drum, as uncertainties exist in the magnitude of catch-and-release recreational fishing and commercial discards (Takade and Paramore 2007; Bacheler et al., in press). Besides providing an abundance index for use in assessments, fishery-independent surveys have also 
provided ecologists with the opportunity to explain and predict recruitment variability in fish populations.

\section{Patterns of Red Drum Recruitment}

Cluster analyses determined that three temporal patterns of red drum recruitment have occurred during the past 16 years in North Carolina. All clusters showed a general dome-shaped seasonal pattern, suggesting that the survey captured the major pulse of red drum recruits in each year. Scharf (2000) also documented dome-shaped patterns of monthly CPUE for age- 0 red drum across multiple Texas estuaries. In both studies, the ascending limb of the CPUE curve probably represents initial settlement of new recruits combined with increased vulnerability to the seine gear, while the descending limb is probably attributable to a combination of mortality, emigration from shallow water, and size-based gear avoidance. It is likely that the three clusters documented in our study represent annual variation in the timing of spawning and settlement, the magnitude of recruitment, and the rate of mortality or emigration.

Two primary observations were made from our analyses of the spatial patterns of red drum recruitment in North Carolina. First, there was some variation in catches of juvenile red drum on a relatively small spatial scale that might be explained by spawning locations of adults, egg and larval transport mechanisms, habitat selection by larvae or juveniles, or a combination thereof (Rooker and Holt 1997; Rooker et al. 1998; Stunz et al. 2002). Second, despite smallscale variation, red drum CPUE was correlated at a large, intrastate scale of tens to hundreds of kilometers but not at a much larger spatial scale (i.e., among states). Myers et al. (1997) demonstrated that the spatial scale of recruitment for marine fishes was often approximately $500 \mathrm{~km}$, which is consistent with patterns that indicated strong correlations in red drum abundance among Texas estuaries that extended across hundreds of kilometers (Scharf 2000). The high degree of correlation in abundance of red drum among regions in our study and among estuaries in Texas (Scharf 2000) signifies that conditions for growth and survival of eggs and larvae probably vary on a regional scale.

Although fish were captured across widely varying environmental conditions, early juvenile red drum showed broad patterns of temperature and salinity preference. However, we suspect that what appears to be a temperature preference may simply be a byproduct of the seasonal timing of maximum recruitment, which generally occurs in early October at around $20^{\circ} \mathrm{C}$. The small temperature differences across stations further suggest that the temperature preferences we observed were probably uninformative. Alternatively, the highest abundance of age- 0 red drum in oligohaline and mesohaline environments probably reflects a combination of spawning location, egg and larval transport patterns, and juvenile habitat selection. Our observations indicate that age- 0 red drum initiate movement to upper estuary habitats during the fall, similar to observations by Stewart and Scharf (2008). Because few samples were taken during periods of low dissolved oxygen, we were unable to draw any broad conclusions about the age- 0 red drum response to oxygen level.

Loss rates of age- 0 red drum from shallow habitats of estuaries and creeks in North Carolina appeared to vary independent of cohort density. Other studies have also found weak or absent regulation in some marine fish populations (e.g., Shepherd and Cushing 1990; MacKenzie and Koster 2004), but density-dependent loss has been detected for several species (e.g., McBride et al. 1995; Buckel et al. 1999; Scharf 2000; Craig et al. 2007). Specifically, Scharf (2000) examined a time series incorporating over 20 years of fishery-independent data collected along the Texas coast and found weak or nonexistent relationships between the fall CPUE of age- 0 red drum and the catch of age-1 fish during the next year, indicating the potential for density-dependent regulation during a cohort's first year.

Our field sampling protocol, like Scharf's (2000), was not ideal for testing for density dependence in loss rates. We could not separate mortality from emigration, so the proportion of loss contributed by mortality could not be determined. However, we did not observe sharp decreases in CPUE after cold periods during fall, suggesting that offshore emigration of red drum before the end of November was minimal. Furthermore, red drum mortality may have been density dependent but masked by unmeasured covariation in environmental characteristics (i.e., cryptic density dependence: Shima and Osenberg 2003). It should be noted that the 2 years with the lowest observed age-0 red drum CPUE produced the two lowest estimated loss rates, suggestive of density-dependent loss rates at low abundances. A recent field study by Stewart and Scharf (2008) also noted the potential for red drum to experience densitydependent juvenile mortality in the New River estuary. Further study on the magnitude of red drum population regulation during the juvenile stage is clearly warranted.

\section{When is Recruitment Determined for Red Drum?}

Recruitment appears to be determined during the early life stages of red drum. Loss rates of age- 0 red drum appeared to be density independent, and age- 0 
CPUE was positively correlated with age-2 abundance 2 years later. These results are consistent with previous research suggesting that recruitment is primarily set by the end of the larval stage (Hjort 1914; Cushing 1972; Crecco et al. 1983; Leggett and Deblois 1994; Miller et al. 1988). Due to the observational nature of our data, future work will be required to determine whether the relationship is robust.

Although we found a correlation between age-0 catch and the catch of age- 2 fish obtained 2 years later, there was still considerable unexplained variation about the relationship, indicating that further modification of recruitment occurs in later life stages. The ecology of later-stage juveniles and subadults is poorly known, but density-dependent or density-independent forces acting upon these stages may continue to modify recruitment success (Sissenwine 1984; Myers and Cadigan 1993; Dingsør et al. 2007). Abundance of first- or secondwinter red drum may be decreased by cold-induced winter mortality, because North Carolina is the northernmost overwintering grounds for the species. Other temperate marine fishes along the U.S. Atlantic coast, including Atlantic croakers Micropogonias undulatus and striped bass Morone saxatilis, have been found to experience mortality from cold winters at the northern extent of their ranges (Hurst and Conover 1998; Lankford and Targett 2001). However, capturing the possible effects of winter temperatures is difficult, and we recommend experimentation in a controlled laboratory environment to more thoroughly understand the influence of cold water temperatures on the survival of juvenile red drum. Theoretically, predation upon juvenile red drum by piscivorous fishes, birds, marine mammals, or humans may also increase or dampen variability in recruitment (Bailey 1994; Sogard 1997). Future research should quantify the sources and magnitude of juvenile mortality.

Temporal variability in spawning stock biomass and environmental conditions may each contribute substantially to the year-to-year variation observed in the red drum JAI. However, we lacked a concurrent time series of spawning stock biomass because federal regulations prohibit the harvest of large adults. We also did not believe that exploratory correlation analysis of environmental factors, such as coastal wind patterns or freshwater discharge into sounds and estuaries, was a fruitful pursuit given the lack of mechanistic information on environmental factors that potentially contribute most to juvenile abundance (Myers 1998; Cardinale and Hjelm 2006). If and when an adult red drum abundance index becomes available in North Carolina, it may be useful as a relative measure of spawning stock biomass for statistical recruitment correlations.

\section{Acknowledgments}

We thank NCDMF personnel for design and implementation of the JAI survey and its interpretation, especially Jeff Ross, Carol Etheridge, Jeff Ferrence, and John Schoolfield. Warren Mitchell, Beth Gardner, John Wiedenmann, and Kevin Gross provided statistical advice. Fieldwork and data collection were supported by funds made possible by the Federal Aid in Sport Fish Restoration Act, and analyses were supported by grants from North Carolina Sea Grant (R/ MRD-48 and R/MRD-52).

\section{References}

ASMFC (Atlantic States Marine Fisheries Commission). 2007. 2007 review of the Atlantic States Marine Fisheries Commission fishery management plan for red drum (Sciaenops ocellatus). ASMFC, Washington, D.C.

Bacheler, N. M., J. E. Hightower, L. M. Paramore, J. A. Buckel, and K. H. Pollock. In press. An age-dependent tag return model for estimating mortality and selectivity of an estuarine-dependent fish with high rates of catch and release. Transactions of the American Fisheries Society.

Bailey, K. M. 1994. Predation on juvenile flatfish and recruitment variability. Netherlands Journal of Sea Research 32(2):175-189.

Barrios, A. T. 2004. Use of passive acoustic monitoring to resolve spatial and temporal patterns of spawning activity for red drum, Sciaenops ocellatus, in the Neuse River Estuary, North Carolina. Master's thesis. North Carolina State University, Raleigh.

Buckel, J. A., D. O. Conover, N. D. Steinberg, and K. A. McKown. 1999. Impact of age-0 bluefish (Pomatomus saltatrix) predation on age- 0 fishes in the Hudson River estuary: evidence for density-dependent loss of juvenile striped bass (Morone saxatilis). Canadian Journal of Fisheries and Aquatic Sciences 56:275-287.

Burnham, K. P., and D. R. Anderson. 2002. Model selection and inference: a practical information-theoretic approach, 2nd edition. Springer-Verlag, New York.

Cardinale, M., and J. Hjelm. 2006. Marine fish recruitment variability and climate change. Marine Ecology Progress Series 309:307-309.

Craig, J. K., J. A. Rice, L. B. Crowder, and D. A. Nadeau. 2007. Density-dependent growth and mortality in an estuary-dependent fish: an experimental approach with juvenile spot Leiostomus xanthurus. Marine Ecology Progress Series 343:251-262.

Crecco, V., T. Savoy, and L. Gunn. 1983. Daily mortality rates of larval and juvenile American shad (Alosa sapidissima) in the Connecticut River with changes in year-class strength. Canadian Journal of Fisheries and Aquatic Sciences 40:1719-1728.

Cushing, D. H. 1972. The production cycle and the numbers of marine fish. Symposia of the Zoological Society of London 29:213-232.

Daniel, L. B., III. 1988. Aspects of the biology of juvenile red drum, Sciaenops ocellatus, and spotted seatrout, Cynoscion nebulosus (Pisces: Sciaenidae) in South Carolina. 
Master's thesis. College of Charleston, Charleston, South Carolina.

Dingsør, G. E., L. Ciannelli, K. S. Chan, G. Ottersen, and N. C. Stenseth. 2007. Density dependence and density independence during the early life stages of four marine fish stocks. Ecology 88:625-634.

Hastie, T., and R. Tibshirani. 1990. Generalized additive models. Chapman and Hall, London.

Hilborn, R., and C. J. Walters. 1992. Quantitative fisheries stock assessment: choice, dynamics, and uncertainty. Chapman and Hall, New York.

Hjort, J. 1914. Fluctuations in the great fisheries of northern Europe. Rapports et Procès-Verbaux des Réunions, Conseil International pour l'Exploration de la Mer 20.

Holt, S. A., C. L. Kitting, and C. R. Arnold. 1983. Distribution of young red drum among different sea-grass meadows. Transactions of the American Fisheries Society 112:267271.

Houde, E. D. 1987. Fish early life dynamics and recruitment variability. Pages 17-29 in R. D. Hoyt, editor. 10th annual larval fish conference. American Fisheries Society, Symposium 2, Bethesda, Maryland.

Hurst, T. P., and D. O. Conover. 1998. Winter mortality of young-of-the-year Hudson River striped bass (Morone saxatilis): size-dependent patterns and effects on recruitment. Canadian Journal of Fisheries and Aquatic Sciences 55:1122-1130.

Johnson, D. R., and N. A. Funicelli. 1991. Spawning of the red drum in Mosquito Lagoon, east-central Florida. Estuaries 14:74-79.

Lankford, T. E., Jr., and T. E. Targett. 2001. Low-temperature tolerance of age- 0 Atlantic croakers: recruitment implications for U.S. mid-Atlantic estuaries. Transactions of the American Fisheries Society 130:236-249.

Leggett, W. C., and E. Deblois. 1994. Recruitment in marine fishes: is it regulated by starvation and predation in the egg and larval stages? Netherlands Journal of Sea Research 32(2):119-134.

Luczkovich, J. J., H. J. Daniel, III, and M. W. Sprague. 1999. Characterization of critical spawning habitats of weakfish, spotted seatrout and red drum in Pamlico Sound using hydrophone surveys. Completion Report, F-62, North Carolina Division of Marine Fisheries, Morehead City.

Lux, F. E., and J. V. Mahoney. 1969. First records of the channel bass, Sciaenops ocellatus (Linnaeus), in the Gulf of Maine. Copeia 1969:632-633.

MacKenzie, B. R., and F. W. Koster. 2004. Fish production and climate: sprat in the Baltic Sea. Ecology 85:784-794.

Martinez-Andrade, F., P. Campbell, and B. Fuls. 2005. Trends in relative abundance and size of selected finfishes and shellfishes along the Texas coast: November 1975December 2003. Texas Parks and Wildlife Management Data Series 232.

McBride, R. S., M. Scherer, and C. Powell. 1995. Correlated variations in abundance, size, growth, and loss rates of age-0 bluefish in a southern New England estuary. Transactions of the American Fisheries Society 124:898910.

McCune, B., and J. B. Grace. 2002. Analysis of ecological communities. MjM Software Design, Gleneden Beach, Oregon.
McEachron, L. W., R. L. Colura, B. W. Bumbuardner, and R. Ward. 1998. Survival of stocked red drum in Texas. Bulletin of Marine Science 62:359-368.

Miller, T. J., L. B. Crowder, J. A. Rice, and E. A. Marshall. 1988. Larval size and recruitment mechanisms in fishes: toward a conceptual framework. Canadian Journal of Fisheries and Aquatic Sciences 45:1657-1670.

Murphy, M. D., and R. G. Taylor. 1990. Reproduction, growth, and mortality of red drum Sciaenops ocellatus in Florida waters. U.S. National Marine Fisheries Service Fishery Bulletin 88:531-542.

Myers, R. A. 1998. When do environment-recruitment correlations work? Reviews in Fish Biology and Fisheries 8:285-305.

Myers, R. A., and N. G. Cadigan. 1993. Density-dependent juvenile mortality in marine demersal fish. Canadian Journal of Fisheries and Aquatic Sciences 50:1576-1590.

Myers, R. A., G. Mertz, and J. Bridson. 1997. Spatial scales of interannual recruitment variations in marine, anadromous, and freshwater fish. Canadian Journal of Fisheries and Aquatic Sciences 54:1400-1407.

NCDMF (North Carolina Division of Marine Fisheries). 2001. Red drum fishery management plan. North Carolina Department of Natural and Environmental Resources, Morehead City.

Pearson, J. C. 1929. Natural history and conservation of the redfish and other commercially important sciaenids on the Texas coast. U.S. Bureau of Fisheries Bulletin 44:129-214.

Peters, K. M., and R. H. McMichael, Jr. 1987. Early life history of the red drum, Sciaenops ocellatus (Pisces: Sciaenidae), in Tampa Bay, Florida. Estuaries 10(2):92107.

Ricker, W. E. 1975. Computation and interpretation of biological statistics of fish populations. Fisheries Research Board of Canada Bulletin 191.

Rooker, J. R., and S. A. Holt. 1997. Utilization of subtropical seagrass meadows by newly settled red drum Sciaenops ocellatus: patterns of distribution and growth. Marine Ecology Progress Series 158:139-149.

Rooker, J. R., S. A. Holt, M. A. Soto, and G. J. Holt. 1998. Postsettlement patterns of habitat use by sciaenid fishes in subtropical seagrass meadows. Estuaries 21(2):318327.

Ross, J. L., and T. M. Stevens. 1992. Life history and population dynamics of red drum (Sciaenops ocellatus) in North Carolina waters. North Carolina Division of Marine Fisheries, Marine Fisheries Completion Report Project F-29, Morehead City.

Ross, J. L., T. M. Stevens, and D. S. Vaughan. 1995. Age, growth, mortality, and reproductive biology of red drums in North Carolina waters. Transactions of the American Fisheries Society 124:37-54.

Scharf, F. S. 2000. Patterns in abundance, growth, and mortality of juvenile red drum across estuaries on the Texas coast with implications for recruitment and stock enhancement. Transactions of the American Fisheries Society 129:1207-1222.

Shepherd, J. G., and D. H. Cushing. 1990. Regulation in fish populations: myth or mirage? Philosophical Transactions of the Royal Society of London 330:151-164.

Shima, J. S., and C. W. Osenberg. 2003. Cryptic density 
dependence: effects of covariation between density and site quality in reef fish. Ecology 84:46-52.

Sissenwine, M. P. 1984. Why do fish populations vary? Pages 59-94 in R. M. May, editor. Exploitation of marine communities. Springer-Verlag, Berlin.

Sogard, S. M. 1997. Size-selective mortality in the juvenile stage of teleost fishes: a review. Bulletin of Marine Science 60:1129-1157.

Stewart, C. B., and F. S. Scharf. 2008. Estuarine recruitment, growth, and first year survival of age-0 juvenile red drum (Sciaenops ocellatus) in North Carolina. Transactions of the American Fisheries Society 137:1089-1103.

Stunz, G. W., T. J. Minello, and P. S. Levin. 2002. A comparison of early juvenile red drum densities among various habitat types in Galveston Bay, Texas. Estuaries 25(1):76-85.

Takade, H. M., and L. M. Paramore. 2007. Stock status of the northern red drum stock. North Carolina Division of Marine Fisheries, Morehead City.

Vaughan, D. S., and J. T. Carmichael. 2000. Assessment of Atlantic red drum for 1999: northern and southern regions. NOAA Technical Memorandum NMFS-SEFSC447, Beaufort, North Carolina.

Wenner, C. A., W. A. Roumillat, J. E. Moran, Jr., M. B. Maddox, L. B. Daniel, III, and J. W. Smith. 1990 Investigations on the life history and population dynamics of marine recreational fishes in South Carolina: Part 1. South Carolina Wildlife and Marine Resources Department, Marine Resources Research Institute, Final Report, Project F-37, Charleston.

Wiedenmann, J., and T. E. Essington. 2006. Densitydependent overwinter survival in young-of-year bluefish (Pomatomus saltatrix)? A new approach for assessing stage-structured survival. Canadian Journal of Fisheries and Aquatic Sciences 63:1934-1943. 